\title{
Multiple Solutions of Boundary Value Problems for $n$ th-Order Singular Nonlinear Integrodifferential Equations in Abstract Spaces
}

\author{
Yanlai Chen, ${ }^{1}$ Tingqiu Cao, ${ }^{1}$ and Baoxia Qin ${ }^{2}$ \\ ${ }^{1}$ School of Economics, Shandong University, Jinan, Shandong 250100, China \\ ${ }^{2}$ Department of Mathematics, Qilu Normal University, Jinan, Shandong 250013, China \\ Correspondence should be addressed to Yanlai Chen; yanlaichen@126.com
}

Received 12 December 2014; Accepted 24 August 2015

Academic Editor: Mufid Abudiab

Copyright ( $) 2015$ Yanlai Chen et al. This is an open access article distributed under the Creative Commons Attribution License, which permits unrestricted use, distribution, and reproduction in any medium, provided the original work is properly cited.

The authors discuss multiple solutions for the $n$ th-order singular boundary value problems of nonlinear integrodifferential equations in Banach spaces by means of the fixed point theorem of cone expansion and compression. An example for infinite system of scalar third-order singular nonlinear integrodifferential equations is offered.

\section{Introduction}

Singular nonlinear boundary value problems of the ordinary differential equations appeared frequently in applications. With Taliaferro [1] treating the general problem, Callegari and Nachman [2] considered existence questions in boundary layer theory, and Luning and Perry [3] obtained constructive results for generalized Emden-Fowler problems. Results have also been obtained for singular boundary value problems arising in reaction-diffusion theory and in nonNewtonian fluid theory [4]. Singular nonlinear boundary value problems of the ordinary differential equations have made great progress in recent years (please see [5-8]).

In the above papers, singular problems are studied in scalar case. In Chen [9], the boundary value problems of a class of $n$ th-order nonlinear integrodifferential equations of mixed type in Banach space are considered, and the existence of three solutions is obtained by using the fixed point index theory. But such equations do not have singular nonlinear terms. As much as we know, there are a few papers ([10-18]) to consider the singular problems in abstract Banach spaces. In Liu [10], the following singular problems in Banach spaces E

$$
\begin{aligned}
-x^{\prime \prime}(t) & =f\left(t, x(t), x^{\prime}(t)\right), \quad \forall 0<t \leq T ; \\
x(0) & =x^{\prime}(0)=\theta,
\end{aligned}
$$

were investigated by constructing a special convex closed set and using Mönch fixed point theorem, where $\theta$ denotes the zero element of $E$. In [10], (1) under certain conditions, there is at least one solution. And, in the methods, under normal circumstances, to investigate the singular problems, at first, one needs to consider the approximation problems which have no singularities. However, in the study of integrodifferential equations in infinite dimensional Banach space, this method is very complicated and difficult.

In this paper, not considering approximative problems, informed by the characteristic of nonlinear term, we construct a new cone, and through the cone we create a new special cone. Moreover, through finding the relations from $\|u\|_{c}$ to $\left\|u^{(n-2)}\right\|_{c}$ ( $u$ belongs to the special cone), we triumphantly overcome the singularity and use the fixed point theorem of cone expansion and compression directly to obtain the existence of multiple solutions for singular boundary value problems of nonlinear integrodifferential equations in Banach spaces. Finally, an example of scalar third-order singular nonlinear integrodifferential equations for an infinite system is offered. With the previous methods, one can not get the results in this paper.

Let $P$ be a cone in Banach space $E$ which defines a partial ordering in $E$ by $x \leq y$ if and only if $y-x \in P$. Let $P_{r}=\{u \in$ $P:\|u\|<r\}(r>0)$. $P$ is said to be normal if there exists a positive constant $N$ such that $\theta \leq x \leq y$ implies $\|x\| \leq N\|y\|$, 
where $\theta$ denotes the zero element of $E$, and the smallest $N$ is called the normal constant of $P$. For convenience, in the following, we set $P$ as a normal cone and $N=1$. Let $P_{1}=$ $\left\{u \in P: u \geq u_{0}\|u\|\right\}$, in which $u_{0} \in P$ and $0<\left\|u_{0}\right\|<1$. Obviously, $P_{1}$ is a normal cone of $E$, and the normal constant of $P_{1}$ also is 1 . Cone $P_{1}$ is the key to overcome the singular nonlinear term (please see the last example).

We consider the following singular boundary value problem (SBVP for short) for an $n$ th-order nonlinear integrodifferential equations in Banach spaces $E$ :

$$
\begin{aligned}
& -u^{(n)}(t) \\
& =f\left(t, u(t), u^{\prime}(t), \ldots, u^{(n-2)}(t),(T u)(t),(S u)(t)\right), \\
& \quad 0<t<1 ; \\
& u^{(i)}(0)=\theta, \quad(i=0,1, \ldots, n-2), \\
& u^{(n-1)}(1)=\theta
\end{aligned}
$$

where $J:=[0,1], f \quad \in \quad C[(0,1) \times$ $\underbrace{P_{1} \backslash\{\theta\} \times P_{1} \backslash\{\theta\} \times \cdots \times P_{1} \backslash\{\theta\} \times P_{1} \times P_{1}}_{n+1}, P_{1}]$,

$$
\begin{aligned}
& (T u)(t)=\int_{0}^{t} k(t, s) u(s) \mathrm{d} s \\
& (S u)(t)=\int_{0}^{1} h(t, s) u(s) \mathrm{d} s,
\end{aligned}
$$

$\forall t \in J$

with $k \in C\left[D, R_{+}\right](D=\{(t, s) \in J \times J: t \geq s\}), h \in C[J \times$ $\left.J, R_{+}\right]$( $R_{+}$denotes the set of all nonnegative real numbers).

$f\left(t, v_{0}, v_{1}, \ldots, v_{n-1}, v_{n}\right)$ is singular at $v_{i}=\theta(i=0,1, \ldots$, $n-2), t=0$, and/or $t=1$ if

$$
\lim _{v_{i} \rightarrow \theta}\left\|f\left(t, v_{0}, \ldots, v_{n}\right)\right\|=+\infty, \quad(i=0,1, \ldots, n-2),
$$

$\forall t \in(0,1), v_{k} \in P_{1}(k=n-1, n), v_{j} \in P_{1} \backslash\{\theta\}(j=0,1, \ldots$, $n-2)$,

$$
\begin{aligned}
\lim _{t \rightarrow 0^{+}}\left\|f\left(t, v_{0}, \ldots, v_{n}\right)\right\| & =+\infty, \\
\text { and/or } \lim _{t \rightarrow 1^{-}}\left\|f\left(t, v_{0}, \ldots, v_{n}\right)\right\| & =+\infty,
\end{aligned}
$$

$\forall v_{i} \in P_{1} \backslash\{\theta\}(i=0,1, \ldots, n-2), v_{j} \in P_{1}(j=n-1, n)$.

Let $J^{\prime}=(0,1)$. A map $u \in C^{n-2}[J, E] \cap C^{n}\left[J^{\prime}, E\right]$ is called a solution of SBVP (2) if it satisfies (2).

\section{Preliminaries and Several Lemmas}

Denote $C^{n-2}[J, E]:=\{u: u$ is a map from $J$ into $E$ and $u^{(n-2)}(t)$ is continuous on $\left.J\right\}$. The norm of $u \in C^{n-2}[J, E]$ is defined by

$$
\|u\|_{n-2}=\max _{i=0,1, \ldots, n-2}\left\{\left\|u^{(i)}\right\|_{c}\right\}
$$

where

$$
\left\|u^{(i)}\right\|_{c}=\max _{t \in J}\left\{\left\|u^{(i)}(t)\right\|\right\}, \quad(i=0, \ldots, n-2) .
$$

Obviously $\left(C^{n-2}[J, E],\|\cdot\|\right)$ is a Banach space.

Let

$$
\begin{aligned}
& C^{n-2}\left[J, P_{1}\right]:=\left\{u^{(i)} \in C[J, E]: u^{(i)}(t) \in P_{1}, t \in J, i\right. \\
& \quad=0,1,2, \ldots, n-2\} .
\end{aligned}
$$

Obviously, $C^{n-2}\left[J, P_{1}\right]$ is a cone of $C^{n-2}[J, E]$. For $r>0$, we write $P_{1_{r}}:=\left\{u \in P_{1}:\|u\|<r\right\}$ and $\overline{P_{1_{r}}}:=\left\{u \in P_{1}:\|u\| \leq r\right\}$.

Let $u:(0,1] \rightarrow E$ be continuous. We call the abstract generalized integral $\int_{0}^{1} u(t) \mathrm{d} t$ convergence if $\lim _{s \rightarrow 0^{+}} \int_{s}^{1} u(t) \mathrm{d} t$ exists. Analogously, we can define the convergence of other kinds of abstract generalized integrals.

We will use $\alpha$ to denote the Kuratowski measure of noncompactness of set in space E. For details of the Kuratowski measure of noncompactness, please see [19].

Lemma 1 (see [19]). Let $H$ be a bounded set of $C^{m}[J, E]$. Suppose that $H^{(m)}:=\left\{u^{(m)}: u \in H\right\}$ is equicontinuous. Then,

$$
\begin{aligned}
\alpha_{m}(H) & =\max _{i=0,1, \ldots, m}\left\{\alpha\left(H^{(i)}(J)\right)\right\} \\
& =\max _{i=0,1, \ldots, m}\left\{\max _{t \in J}\left\{\alpha\left(H^{(i)}(t)\right)\right\}\right\},
\end{aligned}
$$

where

$$
\begin{aligned}
& H^{(i)}(J):=\left\{u^{(i)}(t): t \in J, u \in H\right\}, \\
& \quad(i=0,1,2, \ldots, m), \\
& H^{(i)}(t):=\left\{u^{(i)}(t): u \in H\right\}, \quad(i=0,1,2, \ldots, m) .
\end{aligned}
$$

Lemma 2 (see [19]). If $H \subset C[J, E]$ is bounded and equicontinuous, then $\alpha(H(t))$ is continuous on J. Moreover,

$$
\alpha\left(\left\{\int_{J} u(t) \mathrm{d} t: u \in H\right\}\right) \leq \int_{J} \alpha(H(t)) \mathrm{d} t .
$$

Lemma 3 (see [19]). Let $H$ be a bounded set of $C^{m}[J, E]$. Then,

$$
\begin{aligned}
& \alpha_{m}(H) \geq \alpha(H(J)), \\
& \alpha_{m}(H) \geq \alpha\left(H^{\prime}(J)\right), \ldots, \alpha_{m}(H) \geq \alpha\left(H^{(m-1)}(J)\right), \\
& \alpha_{m}(H) \geq \frac{1}{2} \alpha\left(H^{(m)}(J)\right),
\end{aligned}
$$

where $H^{(i)}(J)(i=0,1,2, \ldots, m)$ is defined by Lemma 1 .

Lemma 4 (the fixed point theorem of cone expansion and compression [see [20]]). $P$ is a cone of real Banach space E. Let

$$
\overline{P_{R}} \backslash P_{r}:=\{x \in P: r \leq\|x\| \leq R\}, \quad R>r>0 .
$$

Suppose that $A: \overline{P_{R}} \backslash P_{r} \rightarrow P$ is a strict set contraction such that one of the following two conditions is satisfied: 
(i) $A x \geq x, \forall x \in P,\|x\|=r$ and $A x \not x, \forall x \in P$, $\|x\|=R$;

(ii) $A x \nsupseteq x, \forall x \in P,\|x\|=R$ and $A x \not x, \forall x \in P$, $\|x\|=r$.

Then, $A$ has at least a fixed point in $\overline{P_{R}} \backslash P_{r}$.

\section{Main Results and an Example}

To continue, let us formulate some conditions.

$\left(H_{1}\right)$ There exist $b \in L\left[J^{\prime}, R_{+}\right], a_{i} \in L\left[J^{\prime}, R_{+}\right](i=0,1, \ldots$, $n), g_{i} \in C[(0,+\infty),(0,+\infty)](i=0,1, \ldots, n-2)$, and $h_{i} \in$ $C[[0,+\infty),[0,+\infty)],(i=0,1, \ldots, n)$, such that

$$
\begin{aligned}
& \left\|f\left(t, v_{0}, v_{1}, \ldots, v_{n-2}, v_{n-1}, v_{n}\right)\right\| \\
& \leq b(t)+\sum_{i=0}^{n-2} a_{i}(t)\left(g_{i}\left(\left\|v_{i}\right\|\right)+h_{i}\left(\left\|v_{i}\right\|\right)\right) \\
& \quad+a_{n-1}(t) h_{n-1}\left(\left\|v_{n-1}\right\|\right)+a_{n}(t) h_{n}\left(\left\|v_{n}\right\|\right),
\end{aligned}
$$

$\forall t \in(0,1), v_{i} \in P_{1} \backslash\{\theta\} \quad(i=0,1, \ldots, n-2), v_{n-1}, v_{n} \in P_{1}$,

where $g_{i}$ is nonincreasing and $h_{i} / g_{i}(i=0,1, \ldots, n-2)$ and $h_{n-1}, h_{n}$ are nondecreasing.

$\left(\mathrm{H}_{2}\right)$ For any $\mathrm{R}>r>0$,

$$
\begin{aligned}
& \int_{0}^{1} s(b(s) \\
& \quad+\sum_{i=0}^{n-2} a_{i}(s) g_{i}\left(\frac{s^{n-1-i}}{(n-1-i) !} r\right)\left(1+\frac{h_{i}(R)}{g_{i}(R)}\right) \\
& \left.\quad+a_{n-1}(s) h_{n-1}\left(k^{*} R\right)+a_{n}(s) h_{n}\left(h^{*} R\right)\right) \mathrm{d} s \\
& \quad<+\infty .
\end{aligned}
$$

And, there exists a $R_{0}>0$ such that

$$
\begin{aligned}
& \int_{0}^{1} s(b(s) \\
& \quad+\sum_{i=0}^{n-2} a_{i}(s) g_{i}\left(\frac{s^{n-1-i}}{(n-1-i) !} R_{0}\right)\left(1+\frac{h_{i}\left(R_{0}\right)}{g_{i}\left(R_{0}\right)}\right) \\
& \left.\quad+a_{n-1}(s) h_{n-1}\left(k^{*} R_{0}\right)+a_{n}(s) h_{n}\left(h^{*} R_{0}\right)\right) \mathrm{d} s \\
& \quad<R_{0},
\end{aligned}
$$

where $b, a_{i}(i=0,1, \ldots, n), g_{i}(i=0,1, \ldots, n-2)$, and $h_{i}(i=$ $0,1, \ldots, n)$ are defined as in condition $\left(H_{1}\right)$, and

$$
\begin{aligned}
k^{*} & :=\max _{(t, s) \in D}\{k(t, s)\}, \\
h^{*} & :=\max _{(t, s) \in J \times J}\{h(t, s)\} .
\end{aligned}
$$

$\left(H_{3}\right)$ For any $R>r>0,[a, b] \subset(0,1), f$ is uniformly continuous on

$[a, b]$

$$
\times \underbrace{\overline{P_{1_{R}}} \backslash P_{1_{r}} \times \overline{P_{1_{R}}} \backslash P_{1_{r}} \times \cdots \times \overline{P_{1_{R}}} \backslash P_{1_{r}} \times \overline{P_{1_{R}}} \times \overline{P_{1_{R}}}}_{n+1}
$$

and there exist $L_{i} \geq 0(i=0,1, \ldots, n)$, such that

$$
\begin{aligned}
& \alpha\left(f\left(t, B_{0}, B_{1}, \ldots, B_{n}\right)\right) \leq \sum_{i=0}^{n} L_{i} \alpha\left(B_{i}\right), \\
& \forall t \in(0,1), B_{i} \subset \overline{P_{1_{R}}} \backslash P_{1_{r}}(i=0,1, \ldots, n-2), B_{n-1}, B_{n} \subset \overline{P_{1_{R}}} .
\end{aligned}
$$

Remark 5. Obviously, condition $\left(\mathrm{H}_{3}\right)$ is satisfied automatically when $E$ is finite dimensional.

$\left(H_{4}\right)$ There exist $0<\alpha<1 / 2$, and $\varphi \in P_{1}^{*}\left(P_{1}^{*}\right.$ denotes the dual cone of $\left.P_{1}\right)$ such that $\varphi(v)>0$ for $v>\theta$. At the same time, one of the $n-1$ conditions is satisfied

$$
\begin{aligned}
\frac{\varphi\left(f\left(t, v_{0}, v_{1}, \ldots, v_{n}\right)\right)}{\varphi\left(v_{j}\right)} & \longrightarrow+\infty, \\
& \quad \text { as } \varphi\left(v_{j}\right)>0, v_{j} \in P_{1},\left\|v_{j}\right\| \longrightarrow 0
\end{aligned}
$$

uniformly in $t \in[\alpha, 1-\alpha]$, with $j \in\{0,1, \ldots, n-2\}$.

Remark 6. Because $f\left(t, v_{0}, v_{1}, \ldots, v_{n}\right)$ is singular at $v_{i}=\theta(i=$ $0,1, \ldots, n-2)$, condition $\left(H_{4}\right)$ is easy to be satisfied. And only one of the $n-1$ conditions is satisfied.

$\left(H_{5}\right)$ There exist $0<\alpha<1 / 2$, and $\varphi \in P_{1}^{*}\left(P_{1}^{*}\right.$ denotes the dual cone of $\left.P_{1}\right)$ such that $\varphi(v)>0$ for $v>\theta$. At the same time, one of the following $n-1$ conditions is satisfied:

$$
\frac{\varphi\left(f\left(t, v_{0}, v_{1}, \ldots, v_{n}\right)\right)}{\varphi\left(v_{j}\right)} \longrightarrow+\infty
$$

$$
\text { as } \varphi\left(v_{j}\right)>0, v_{j} \in P_{1},\left\|v_{j}\right\| \longrightarrow+\infty
$$

uniformly in $t \in[\alpha, 1-\alpha]$, with $j \in\{0,1, \ldots, n-2\}$.

Remark 7. In condition $\left(H_{5}\right)$, only one of the $n-1$ conditions is satisfied.

To avoid singularity, let

$$
\begin{aligned}
Q & =:\left\{u \in C^{n-2}\left[J, P_{1}\right]: u^{(i)}(0)\right. \\
& =\theta,(i=0,1, \ldots, n-2), u^{(i)}(t) \\
& \geq \frac{t^{n-1-i}}{(n-1-i) !} u^{(i)}(s)(i=0,1, \ldots, n-2), t, s \\
& \in J\} .
\end{aligned}
$$

Obviously, $Q$ is a normal cone in $C^{n-2}[J, E]$, and the normal constant of $Q$ is 1 . 
Lemma 8. Suppose $u \in Q$. Then,

$$
\begin{aligned}
& \|u\|_{n-2}=\left\|u^{(n-2)}\right\|_{c}, \\
& \left\|u^{(j)}(t)\right\| \geq \frac{t^{n-1-j}}{(n-1-j) !}\left\|u^{(n-2)}\right\|_{c}, \\
& \qquad(j=0,1, \ldots, n-2), \forall t \in J .
\end{aligned}
$$

Proof. For any $u \in Q$, that is, $u^{(i)}(0)=\theta(i=0,1, \ldots, n-2)$,

$$
\begin{aligned}
&\left\|u^{(i)}(t)\right\|=\left\|\int_{0}^{t} u^{(i+1)}(s) \mathrm{d} s\right\| \leq t\left\|u^{(i+1)}\right\|_{c} \leq\left\|u^{(i+1)}\right\|_{c} \\
&(i=0,1, \ldots, n-3), \forall t \in J .
\end{aligned}
$$

Therefore,

$$
\left\|u^{(i)}\right\|_{c} \leq\left\|u^{(i+1)}\right\|_{c}, \quad(i=0,1, \ldots, n-3),
$$

which implies that

$$
\|u\|_{n-2}=\left\|u^{(n-2)}\right\|_{c}
$$

Because of $u^{(n-2)}(t) \geq t u^{(n-2)}(s), \forall t, s \in J$, and the normal characters of $P$, it is easy to get

$$
\left\|u^{(n-2)}(t)\right\| \geq t\left\|u^{(n-2)}\right\|_{c}, \quad \forall t \in J .
$$

Hence,

$$
\begin{aligned}
u^{(j)}(t) & =\frac{1}{(n-3-j) !} \int_{0}^{t}(t-s)^{n-3-j} u^{(n-2)}(s) \mathrm{d} s \\
& \geq \frac{1}{(n-3-j) !} \int_{0}^{t}(t-s)^{n-3-j} s u^{(n-2)}(\tau) \mathrm{d} s \\
& =\frac{t^{n-1-j}}{(n-1-j) !} u^{(n-2)}(\tau), \\
& \quad(j=0,1, \ldots, n-3), \forall t, \tau \in J .
\end{aligned}
$$

It follows from (28) and (29) and the normal characters of $P$ that

$$
\begin{aligned}
\left\|u^{(j)}(t)\right\| \geq \frac{t^{n-1-j}}{(n-1-j) !}\left\|u^{(n-2)}\right\|_{c}, & \\
& (j=0,1, \ldots, n-2), \forall t \in J .
\end{aligned}
$$

By (27) and (30), the conclusion holds.

Remark 9. Formula (23) implies that the norm of $u \in Q$ is decided by $(n-2)$ th-order derivative $u^{(n-2)}$.

Remark 10 . Inequality (24) implies that $u^{(n-2)}$ controls distance between $\theta$ and $u^{(l)}(l=0,1, \ldots, n-2)$. This is one of the keys to apart from the singularities of the nonlinear term $f$.
Lemma 11. For $j=1,2, \ldots, n-1$, the following conclusion holds:

$$
\frac{t^{j}\left(1-(1-s)^{j}\right)}{j !} \leq G_{j+1}(t, s) \leq \frac{\left(1-(1-s)^{j}\right)}{j !},
$$

where

$$
G_{j}(t, s):= \begin{cases}\frac{t^{j-1}-(t-s)^{j-1}}{(j-1) !}, & 0 \leq s \leq t \leq 1 ; \\ \frac{t^{j-1}}{(j-1) !}, & 0 \leq t \leq s \leq 1 .\end{cases}
$$

Proof. In fact, for $j=1,2, \ldots, n-1, \forall s_{0} \in J$, we get

$$
\begin{aligned}
& \sup _{t \in J} G_{j+1}\left(t, s_{0}\right) \\
& \quad=\max \left\{\sup _{0 \leq s_{0} \leq t \leq 1} \frac{t^{j}-\left(t-s_{0}\right)^{j}}{j !}, \sup _{0 \leq t \leq s_{0} \leq 1} \frac{t^{j}}{j !}\right\} \\
& =\frac{1}{j !} \max \left\{1-\left(1-s_{0}\right)^{j}, s_{0}^{j}\right\} .
\end{aligned}
$$

Consider

$$
1-\left(1-s_{0}\right)^{j} \geq s_{0}^{j}, \quad \forall s_{0} \in J .
$$

It follows from (33) and (34) that

$$
\sup _{t \in J} G_{j+1}\left(t, s_{0}\right)=\frac{1}{j !}\left(1-\left(1-s_{0}\right)^{j}\right), \quad \forall s_{0} \in J ;
$$

that is,

$$
\sup _{t \in J} G_{j+1}(t, s)=\frac{1}{j !}\left(1-(1-s)^{j}\right), \quad \forall s \in J .
$$

On the other hand, for $j=1,2, \ldots, n-1$, it is easy to get

$$
\begin{aligned}
& \inf _{0<t \leq 1} \frac{G_{j+1}(t, s)}{t^{j}} \\
& \quad=\frac{1}{j !} \min \left\{\inf _{0 \leq s<t \leq 1} \frac{t^{j}-(t-s)^{j}}{t^{j}}, \inf _{0<t \leq s \leq 1} \frac{t^{j}}{t^{j}}\right\} \\
& =\frac{1}{j !} \min \left\{\inf _{0 \leq s<t \leq 1}\left(1-\left(1-\frac{s}{t}\right)^{j}\right), 1\right\} \\
& =\frac{1}{j !}\left(1-(1-s)^{j}\right) .
\end{aligned}
$$

It follows from (36) and (37) that

$$
\frac{t^{j}\left(1-(1-s)^{j}\right)}{j !} \leq G_{j+1}(t, s) \leq \frac{\left(1-(1-s)^{j}\right)}{j !},
$$

$\forall t \in(0,1]$.

Since for $t=0$ (38) holds, we get (31). 
Lemma 12. Suppose conditions $\left(H_{1}\right)$ and $\left(H_{2}\right)$ are satisfied. Then, for any $R>r>0, A: \overline{Q_{R}} \backslash Q_{r} \rightarrow Q$, in which the operator $A$ is defined by

$$
\begin{aligned}
& (A u)(t):=\int_{0}^{1} G_{n}(t, s) \\
& \cdot f\left(s, u(s), u^{\prime}(s), \ldots, u^{(n-2)}(s),(T u)(s),(S u)\right.
\end{aligned}
$$

$\cdot(s)) \mathrm{d} s, \quad \forall t \in J$,

where

$$
G_{n}(t, s)=: \begin{cases}\frac{t^{n-1}-(t-s)^{n-1}}{(n-1) !}, & 0 \leq s<t \leq 1 ; \\ \frac{t^{n-1}}{(n-1) !} & 0 \leq t \leq s \leq 1 .\end{cases}
$$

Proof. At first, we show that the operator $A$ defined by (39) is reasonable for $u \in \overline{Q_{R}} \backslash Q_{r}$ with any $R>r>0$. In fact, for $u \in \overline{Q_{R}} \backslash Q_{r}$ with $R \geq\left\|u^{(i)}(t)\right\| \geq\left(t^{n-1-i} /(n-1-i) !\right) r$, by $\left(H_{1}\right)$ and $\left(H_{2}\right)$,

$$
\begin{aligned}
& \int_{0}^{1} s(b(s) \\
& \quad+\sum_{i=0}^{n-2} a_{i}(s) g_{i}\left(\frac{s^{n-1-i}}{(n-1-i) !} r\right)\left(1+\frac{h_{i}(R)}{g_{i}(R)}\right) \\
& \left.\quad+a_{n-1}(s) h_{n-1}\left(k^{*} R\right)+a_{n}(s) h_{n}\left(h^{*} R\right)\right) \mathrm{d} s \\
& \quad<+\infty,
\end{aligned}
$$

which implies that $(A u)(t)$ defined by (39) is reasonable for $t \in J$.

Next, we show that $(A u)(t) \in C^{n-2}\left[J, P_{1}\right]$. For $u^{(i)}(t) \in$ $P_{1}(i=0,1, \ldots, n-2)$,

$$
\begin{aligned}
(\mathrm{Tu})(t) & =\int_{0}^{t} k(t, s) u(s) \mathrm{d} s \geq \int_{0}^{t} k(t, s) u_{0}\|u(s)\| \mathrm{d} s \\
& \geq u_{0}\left\|\int_{0}^{t} k(t, s) u(s) \mathrm{d} s\right\|=u_{0}\|(T u)(t)\|, \\
(S u)(t) & =\int_{0}^{1} h(t, s) u(s) \mathrm{d} s \geq \int_{0}^{1} h(t, s) u_{0}\|u(s)\| \mathrm{d} s \\
& \geq u_{0}\left\|\int_{0}^{1} h(t, s) u(s) \mathrm{d} s\right\|=u_{0}\|(S u)(t)\|,
\end{aligned}
$$

which implies $(T u)(t) \in P_{1}$ and $(S u)(t) \in P_{1}$. This together with

$$
\begin{aligned}
f & \in C[(0,1) \\
& \times \underbrace{P_{1} \backslash\{\theta\} \times P_{1} \backslash\{\theta\} \times \cdots \times P_{1} \backslash\{\theta\} \times P_{1} \times P_{1}}_{n+1}, P_{1}],
\end{aligned}
$$

gives

$$
\begin{aligned}
& (A u)^{(l)}(t)=\int_{0}^{1} G_{n-l}(t, s) \\
& \cdot f\left(u(s), u^{\prime}(s), \ldots, u^{(n-2)}(s),(T u)(s),(S u)(s)\right) \mathrm{d} s \\
& \geq \int_{0}^{1} G_{n-l}(t, s) \\
& \cdot u_{0} \| f\left(u(s), u^{\prime}(s), \ldots, u^{(n-2)}(s),(T u)(s),(S u)\right. \\
& \cdot(s))\left\|\mathrm{d} s \geq u_{0}\right\| \int_{0}^{1} G_{n-l}(t, s) \\
& \cdot f\left(u(s), u^{\prime}(s), \ldots, u^{(n-2)}(s),(T u)(s),(S u)(s)\right) \mathrm{d} s \| \\
& =u_{0}\left\|(A u)^{(l)}(t)\right\|, \quad \forall t \in J,(l=0,1, \ldots, n-2) .
\end{aligned}
$$

Therefore, $(A u)(t) \in C^{n-2}\left[J, P_{1}\right]$ holds.

Finally, by Lemma 11 and (39) and (40), one can see

$$
\begin{aligned}
& (A u)^{(l)}(0)=\theta \quad(l=0,1, \ldots, n-2), \\
& (A u)^{(l)}(t)=\int_{0}^{1} G_{n-l}(t, s) \\
& \cdot f\left(s, u(s), u^{\prime}(s), \ldots, u^{(n-2)}(s),(T u)(s),(S u)\right. \\
& \cdot(s)) \mathrm{d} s \geq \frac{t^{n-1-l}}{(n-1-l) !} \int_{0}^{1} G_{n-l}(\tau, s) \\
& \cdot f\left(s, u(s), u^{\prime}(s), \ldots, u^{(n-2)}(s),(T u)(s),(S u)\right. \\
& \cdot(s)) \mathrm{d} s=\frac{t^{n-1-l}}{(n-1-l) !}(A u)^{(l)}(\tau), \\
& \forall t, \tau \in J, \quad(l=0,1, \ldots, n-2) .
\end{aligned}
$$

It follows from (44) and (45) that $A: \overline{Q_{R}} \backslash Q_{r} \rightarrow Q$.

Lemma 13. Let cone $P$ be normal and let conditions $\left(H_{1}\right)$ and $\left(H_{2}\right)$ be satisfied. Then, $u \in \overline{Q_{R}} \backslash Q_{r}$ is a fixed point of operator $A$ if and only if $u \in C^{n}\left[J^{\prime}, E\right] \cap \overline{Q_{R}} \backslash Q_{r}$ is a solution for $S B V P$ (2).

Proof. By Lemma 12, $A: \overline{Q_{R}} \backslash Q_{r} \rightarrow$ Q. For $u \in C^{n}[J, E]$, Taylor's formula with the integral remainder term gives

$$
u(t)=\sum_{i=0}^{n-1} \frac{t^{i}}{i !} u^{(i)}(0)+\frac{1}{(n-1) !} \int_{0}^{t}(t-s)^{n-1} u^{(n)}(s) \mathrm{d} s,
$$

$\forall t \in J$.

Substituting

$$
u^{(n-1)}(0)=u^{(n-1)}(1)-\int_{0}^{1} u^{(n)}(s) \mathrm{d} s
$$


into (46), we get

$$
\begin{aligned}
& u(t)=\sum_{i=0}^{n-2} \frac{t^{i}}{i !} u^{(i)}(0)+\frac{t^{n-1}}{(n-1) !} u^{(n-1)}(1) \\
& \quad-\frac{1}{(n-1) !}\left(\int_{0}^{1} t^{n-1} u^{(n)}(s) \mathrm{d} s\right. \\
& \left.\quad-\int_{0}^{t}(t-s)^{n-1} u^{(n)}(s) \mathrm{d} s\right), \quad \forall t \in J .
\end{aligned}
$$

Let $u \in C^{n}[(0,1), E] \cap C^{n-2}[J, E]$ be the solution of SBVP (2). Then, (48) implies

$$
\begin{aligned}
& u(t)=\frac{1}{(n-1) !}\left[\int _ { 0 } ^ { 1 } t ^ { n - 1 } f \left(s, u(s), u^{\prime}(s), \ldots, u^{(n-2)}(s),(T u)(s),\right.\right. \\
& (S u)(s)) \mathrm{d} s-\int_{0}^{t}(t-s)^{n-1} \\
& \left.\cdot f\left(s, u(s), u^{\prime}(s), \ldots, u^{(n-2)}(s),(T u)(s),(S u)(s)\right) \mathrm{d} s\right] .
\end{aligned}
$$

Comparing this with (39) and (40), we have $u(t)=(A u)(t)$, which means $u(t)$ is the fixed point of the operator $A$ in $\overline{Q_{R}} \backslash$ $Q_{r}$.

On the other hand, let $u(t) \in \overline{Q_{R}} \backslash Q_{r}$ be the fixed point of the operator $A$. By (39) and (40),

$$
\begin{gathered}
u^{(j)}(t)=(A u)^{(j)}(t)=\frac{1}{(n-1-j) !}\left[\int _ { 0 } ^ { 1 } t ^ { n - 1 - j } f \left(s, u(s), u^{\prime}(s),\right.\right. \\
\left.\ldots, u^{(n-2)}(s),(T u)(s),(S u)(s)\right) \mathrm{d} s-\int_{0}^{t}(t-s)^{n-1-j} \\
\left.\cdot f\left(s, u(s), u^{\prime}(s), \ldots, u^{(n-2)}(s),(T u)(s),(S u)(s)\right) \mathrm{d} s\right]
\end{gathered}
$$

where $j=1,2, \ldots, n-1$. It follows by taking $t=0$ and $t=1$ in (50) that

$$
\begin{aligned}
& u^{(j)}(0)=\theta, \quad(i=0,1, \ldots, n-2), \\
& u^{(n-1)}(1)=\theta, \\
& u^{(n-1)}(t)=\int_{t}^{1} f\left(s, u(s), u^{\prime}(s), \ldots, u^{(n-1)}(s),(T u)\right. \\
& \cdot(s),(S u)(s)) \mathrm{d} s, \quad t \in J^{\prime} ;
\end{aligned}
$$

that is,

$$
\begin{gathered}
u^{(n)}(t)=-f\left(t, u(t), u^{\prime}(t), \ldots, u^{(n-1)}(t),(T u)\right. \\
\cdot(t),(S u)(t)), \quad t \in J^{\prime} .
\end{gathered}
$$

Then, (51)-(52) imply that $u$ is the solution for SBVP (2) in $C^{n}[(0,1), E] \cap C^{n-2}[J, E]$.

Lemma 14. Suppose conditions $\left(H_{1}\right)-\left(H_{3}\right)$ are satisfied. Let

$$
\begin{gathered}
D_{l}(t):=\left\{\int _ { 0 } ^ { 1 } G _ { n - l } ( t , s ) f \left(s, u(s), \ldots, u^{(n-2)}(s),(T u)\right.\right. \\
\cdot(s),(S u)(s)) \mathrm{d} s: u \in B\}, \quad(l=0,1, \ldots, n-2),
\end{gathered}
$$

with $t \in J, B \subset \overline{Q_{R}} \backslash Q_{r}$. Then,

$$
\begin{aligned}
\alpha\left(D_{l}(t)\right) \leq & \sum_{i=0}^{n-2} L_{i} \alpha\left(B^{(i)}(J)\right)+L_{n-1} k^{*} \alpha(B(J)) \\
& +L_{n} h^{*} \alpha(B(J)), \quad(l=0,1, \ldots, n-2),
\end{aligned}
$$

with $B^{(i)}(J):=\left\{u^{(i)}(s): s \in J, u \in B\right\}(i=0,1, \ldots, n-2)$.

Proof. Apart from the singularities, let

$$
\begin{aligned}
& D_{l, \delta}(t)=:\left\{\int_{\delta}^{1-\delta} G_{n-l}(t, s)\right. \\
& \quad f\left(s, u(s), \ldots, u^{(n-1)}(s),(T u)(s),(S u)(s)\right) \mathrm{d} s: \\
& u \in B\}, \quad(l=0,1, \ldots, n-2), 0<\delta<\frac{1}{2}, t \in J .
\end{aligned}
$$

By conditions $\left(H_{1}\right)$ and $\left(H_{2}\right)$, for any $t \in J, u \in B$, one can see that

$$
\| \int_{0}^{1} G_{n-l}(t, s) f\left(s, u(s), \ldots, u^{(n-2)}(s),(T u)(s),(S u)\right.
$$$$
\cdot(s)) \mathrm{d} s-\int_{\delta}^{1-\delta} G_{n-l}(t, s)
$$$$
f\left(s, u(s), \ldots, u^{(n-2)}(s),(T u)(s),(S u)(s)\right) \mathrm{d} s \|
$$$$
\leq \int_{0}^{\delta} s\left(b(s)+\sum_{i=0}^{n-2} a_{i}(s) g_{i}\left(\frac{s^{n-1-i}}{(n-1-i) !} r\right)\right.
$$$$
\cdot\left(1+\frac{h_{i}(R)}{g_{i}(R)}\right)+a_{n-1}(s) h_{n-1}\left(k^{*} R\right)+a_{n}(s)
$$

$$
\begin{aligned}
& \left.\cdot h_{n}\left(h^{*} R\right)\right) \mathrm{d} s+\int_{1-\delta}^{1} s\left(b(s)+\sum_{i=0}^{n-2} a_{i}(s)\right. \\
& \cdot g_{i}\left(\frac{s^{n-1-i}}{(n-1-i) !} r\right)\left(1+\frac{h_{i}(R)}{g_{i}(R)}\right)+a_{n-1}(s) \\
& \left.\cdot h_{n-1}\left(k^{*} R\right)+a_{n}(s) h_{n}\left(h^{*} R\right)\right) \mathrm{d} s
\end{aligned}
$$

$$
(l=0,1, \ldots, n-2) .
$$

By virtue of absolute continuity of the Lebesgue integrable function and (56), it is easy to see that

$$
\begin{aligned}
d_{H\left(D_{l, \delta}(t), D_{l}(t)\right)} & \longrightarrow 0, \\
\text { as } \delta & \longrightarrow 0, \forall t \in J,(l=0,1, \ldots, n-2),
\end{aligned}
$$

in which $d_{H\left(D_{l, \delta}(t), D_{l}(t)\right)}$ denotes the Hausdorff distance between $D_{l, \delta}(t)$ and $D_{l}(t)$. Therefore,

$$
\alpha\left(D_{l}(t)\right)=\lim _{\delta \rightarrow 0} \alpha\left(D_{l, \delta}(t)\right),
$$

$$
\forall t \in J,(l=0,1, \ldots, n-2) .
$$


Now, we check that

$$
\begin{aligned}
\alpha\left(D_{n-2}(t)\right) \leq & \sum_{i=0}^{n-2} L_{i} \alpha\left(B^{(i)}(J)\right)+L_{n-1} k^{*} \alpha(B(J)) \\
& +L_{n} h^{*} \alpha(B(J)) .
\end{aligned}
$$

For $B \subset \overline{Q_{R}} \backslash Q_{r}$, it is easy to see that $A(B) \subset C^{n-1}\left[J, P_{1}\right] \subset$ $C^{n-2}[J, E]$ is bounded, which implies that $D_{l, \delta}(l=0,1, \ldots$, $n-2)$ are bounded. Since

$$
\begin{aligned}
& \int_{\delta}^{1-\delta} G_{n-l}(t, s) \\
& \quad \cdot f\left(s, u(s), \ldots, u^{(n-2)}(s),(T u)(s),(S u)(s)\right) \mathrm{d} s \\
& \quad \in(1-2 \delta) \overline{c o}\left(G_{n-l}(t, s)\right. \\
& \quad \cdot f\left(s, u(s), \ldots, u^{(n-2)}(s),(T u)(s),(S u)(s)\right): s \\
& \quad \in[\delta, 1-\delta]),
\end{aligned}
$$

we have

$$
\begin{aligned}
& \alpha\left(D_{n-2, \delta}(t)\right)=\alpha\left(\left\{\int_{\delta}^{1-\delta} G_{2}(t, s)\right.\right. \\
& \cdot f\left(s, u(s), \ldots, u^{(n-2)}(s),(T u)(s),(S u)(s)\right) \mathrm{d} s: \\
& u \in B\}) \leq \alpha\left(( 1 - 2 \delta ) \overline { c o } \left(G_{2}(t, s)\right.\right. \\
& \cdot f\left(s, u(s), \ldots, u^{(n-2)}(s),(T u)(s),(S u)(s)\right): s \\
& \in[\delta, 1-\delta], u \in B))<\alpha\left(\left(G_{2}(t, s)\right.\right. \\
& \cdot f\left(s, u(s), \ldots, u^{(n-2)}(s),(T u)(s),(S u)(s)\right): s \\
& \quad \in[\delta, 1-\delta], u \in B)) \\
& \quad \leq \alpha\left(f \left(I_{\delta}, B\left(I_{\delta}\right), \ldots, B^{(n-2)}\left(I_{\delta}\right),(T B)\left(I_{\delta}\right),(S u)\right.\right. \\
& \left.\left.\quad\left(I_{\delta}\right)\right)\right),
\end{aligned}
$$

where $I_{\delta}=[\delta, 1-\delta], B^{(l)}\left(I_{\delta}\right)=\left\{u^{(l)}(s): s \in I_{\delta}, u \in B\right\}(l=$ $0,1, \ldots, n-2),(T B)\left(I_{\delta}\right)=\left\{(T u)(s): s \in I_{\delta}, u \in B\right\}$, and $(S B)\left(I_{\delta}\right)=\left\{(S u)(s): s \in I_{\delta}, u \in B\right\}$. Take $r_{1}=\left(\delta^{n-1} /(n-1) !\right) r$, $R_{1}=R \max \left\{1, k^{*}, h^{*}\right\}$, such that

$$
\begin{aligned}
B^{(l)}\left(I_{\delta}\right) & \subset \overline{P_{1 R_{1}}} \backslash P_{1 r_{1}}, \\
& (l=0,1, \ldots, n-2),(T B)\left(I_{\delta}\right),(S B)\left(I_{\delta}\right) \subset \overline{P_{1 R_{1}}} .
\end{aligned}
$$

Obviously, $(T B) \subset C[J, E]$ and $B \subset C[J, E]$; moreover, both of them are equacontinuous on $I_{\delta}$. It follows from $(62),\left(H_{3}\right)$, and Lemmas 1 and 2 that

$$
\begin{aligned}
& \alpha\left(f\left(I_{\delta}, B\left(I_{\delta}\right), \ldots, B^{(n-2)}\left(I_{\delta}\right),(T B)\left(I_{\delta}\right),(S u)\left(I_{\delta}\right)\right)\right) \\
& =\max _{s \in I_{\delta}} \alpha\left(f \left(s, B\left(I_{\delta}\right), \ldots, B^{(n-2)}\left(I_{\delta}\right),(T B)\left(I_{\delta}\right),\right.\right. \\
& \left.\left.\quad(S u)\left(I_{\delta}\right)\right)\right) \leq \sum_{i=0}^{n-2} L_{i} \alpha\left(B^{(i)}\left(I_{\delta}\right)\right)+L_{n-1} \alpha\left((T B)\left(I_{\delta}\right)\right) \\
& \quad+L_{n} \alpha\left((S B)\left(I_{\delta}\right)\right), \\
& \alpha\left((T B)\left(I_{\delta}\right)\right)=\max _{s \in I_{\delta}} \alpha((T B)(s)) \\
& \quad=\max _{s \in I_{\delta}} \alpha\left(\left\{\int_{0}^{s} k(s, \tau) u(\tau) \mathrm{d} \tau: u \in B\right\}\right) \\
& \quad \leq \int_{0}^{s} \alpha(k(s, \tau) B(\tau)) \mathrm{d} \tau \leq k^{*} \alpha(B(J)) .
\end{aligned}
$$

Analogously, it is easy to get

$$
\alpha\left((S B)\left(I_{\delta}\right)\right) \leq h^{*} \alpha(B(J)) .
$$

It follows from $\left(H_{3}\right),(61),(63)$, and (64) that

$$
\begin{aligned}
\alpha\left(D_{n-2, \delta}(t)\right) \leq & \sum_{i=0}^{n-2} L_{i} \alpha\left(B^{(i)}(J)\right)+L_{n-1} k^{*} \alpha(B(J)) \\
& +L_{n} h^{*} \alpha(B(J)) .
\end{aligned}
$$

Hence, by (58), we know (59) is true, and the conclusion holds.

Lemma 15. Let conditions $\left(H_{1}\right),\left(H_{2}\right)$, and $\left(H_{3}\right)$ be satisfied. Suppose that $0 \leq \gamma<1$, in which $\gamma=\sum_{i=0}^{n-3} L_{i}+L_{n-1} k^{*}+$ $L_{n} h^{*}+2 L_{n-2}$. Then, $A$ is a strict set contraction from $\bar{Q}_{R} \backslash Q_{r}$ into $Q$.

Proof. By Lemma 12, $\left(H_{1}\right)$, and $\left(H_{2}\right)$, it is easy to see that $A\left(\overline{Q_{R}} \backslash Q_{r}\right) \subset Q$ and $A$ is a bounded operator. We check that $A\left(\overline{Q_{R}} \backslash Q_{r}\right) \rightarrow Q$ is continuous. In fact, let $u_{m}, u \in \overline{Q_{R}} \backslash Q_{r}$, $\left\|u_{m}-u\right\|_{n-2} \rightarrow 0(m \rightarrow \infty)$. For $i=0,1, \ldots, n-2$, it is easy to get

$$
\begin{aligned}
& R \geq\left\|u_{m}^{(i)}(t)\right\| \geq \frac{t^{n-1-i}}{(n-1-i) !} r, \\
& R \geq\left\|u^{(i)}(t)\right\| \geq \frac{t^{n-1-i}}{(n-1-i) !} r,
\end{aligned}
$$


For $\forall t \in J$, by (31) and (50),

$$
\begin{gathered}
\left\|\left(A u_{m}\right)^{(n-2)}(t)-(A u)^{(n-2)}(t)\right\|=\| \int_{0}^{1} G_{2}(t, s) f(s, \\
\left.u_{m}(s), u_{m}^{\prime}(s), \ldots, u_{m}^{(n-2)}(s),\left(T u_{m}\right)(s),\left(S u_{m}\right)(s)\right) \mathrm{d} s \\
-\int_{0}^{1} G_{2}(t, s) f\left(s, u(s), u^{\prime}(s), \ldots, u^{(n-2)}(s),(T u)\right. \\
\cdot(s),(S u)(s)) \mathrm{d} s\left\|\leq \int_{0}^{1} s\right\| f\left(s, u_{m}(s), u_{m}^{\prime}(s),\right. \\
\left.\ldots, u_{m}^{(n-2)}(s),\left(T u_{m}\right)(s),\left(S u_{m}\right)(s)\right)-f(s, u(s), \\
\left.u^{\prime}(s), \ldots, u^{(n-2)}(s),(T u)(s),(S u)(s)\right) \| \mathrm{d} s .
\end{gathered}
$$

By $(66)$ and conditions $\left(H_{1}\right)$ and $\left(H_{2}\right)$, it is easy to get

$$
\begin{aligned}
& \| f\left(s, u_{m}(s), u_{m}^{\prime}(s), \ldots, u_{m}^{(n-2)}(s),\left(T u_{m}\right)(s),\left(S u_{m}\right)\right. \\
& \cdot(s))-f\left(s, u(s), u^{\prime}(s), \ldots, u^{(n-2)}(s),(T u)\right. \\
& \cdot(s),(S u)(s)) \| \leq 2 s\left(b(s)+\sum_{i=0}^{n-2} a_{i}(s)\right. \\
& \cdot g_{i}\left(\frac{s^{n-1-i}}{(n-1-i) !} r\right)\left(1+\frac{h_{i}(R)}{g_{i}(R)}\right)+a_{n-1}(s) \\
& \left.\cdot h_{n-1}\left(k^{*} R\right)+a_{n}(s) h_{n}\left(h^{*} R\right)\right)
\end{aligned}
$$

From (67), by Lebesgue dominated convergence theorem, combined with the equicontinuity of $\left\{A u_{m}^{(n-2)}\right\}_{m=1}^{+\infty}$ and the continuity of $(A u)^{(n-2)}(t)$, we have

$$
\left\|\left(A u_{m}\right)^{(n-2)}(t)-(A u)^{(n-2)}(t)\right\| \longrightarrow 0,
$$

as $m \longrightarrow \infty$,

uniformly for $t \in J$. Therefore,

$$
\begin{aligned}
\lim _{m \rightarrow \infty}\left\|\left(A u_{m}\right)^{(n-2)}-(A u)^{(n-2)}\right\|_{c} \\
=\lim _{m \rightarrow \infty} \max _{t \in J}\left\|\left(A u_{m}\right)^{(n-2)}(t)-(A u)^{(n-2)}(t)\right\| \\
=\max _{t \in J} \lim _{m \rightarrow \infty}\left\|\left(A u_{m}\right)^{(n-2)}(t)-(A u)^{(n-2)}(t)\right\|=0 .
\end{aligned}
$$

Combining this with (23), we get

$$
\left\|A u_{m}-A u\right\|_{n-2} \longrightarrow 0, \quad \text { as } m \longrightarrow \infty .
$$

Hence, $A: \overline{Q_{R}} \backslash Q_{r} \rightarrow Q$ is continuous.

Let $B \subset \overline{Q_{R}} \backslash Q_{r}$ be bounded, so $A(B) \subset C^{n-1}\left[J, P_{1}\right] \subset$ $C^{n-2}[J, E]$ is bounded. It is easy to prove that $(A(B))^{(n-1)}$ is bounded, so $(A(B))^{(n-2)}$ is equicontinuous. By Lemma 1,

$$
\alpha_{n-2}(A(B))=\max _{l=0,1, \ldots, n-2}\left\{\max _{t \in J}\left\{\alpha\left((A(B))^{(l)}(t)\right)\right\}\right\},
$$

where $\alpha\left((A(B))^{(l)}(t)\right)=\alpha\left(\left\{(A u)^{(l)}(t): u \in S\right\}\right)$ ( $t$ is fixed, $l=0,1, \ldots, n-2)$. On account of Lemmas 14 and 3 , it is easy to see that

$$
\begin{aligned}
& \alpha((A(B))(t))=\alpha\left(D_{0}(t)\right) \\
& \leq \sum_{i=0}^{n-2} L_{i} \alpha\left(B^{(i)}(J)\right)+L_{n-1} k^{*} \alpha(B(J)) \\
& \quad+L_{n} h^{*} \alpha(B(J)) \\
& \leq\left(\sum_{i=0}^{n-3} L_{i}+L_{n-1} k^{*}+L_{n} h^{*}+2 L_{n-2}\right) \alpha_{n-2}(B) \\
& =\gamma \alpha_{n-2}(B) .
\end{aligned}
$$

Similarly,

$$
\alpha\left((A(B))^{(l)}(t)\right) \leq \gamma \alpha_{n-2}(B), \quad(l=1,2, \ldots, n-2) .
$$

Thus, we get $\alpha_{n-2}(A(B)) \leq \gamma \alpha_{n-2}(B)$ by (72), (73), and (74). Since $A$ is bounded and continuous and $0 \leq \gamma<1$, the conclusion holds.

Theorem 16. Suppose that the conditions $\left(H_{1}\right),\left(H_{2}\right),\left(H_{3}\right)$, $\left(H_{4}\right)$, and $\left(H_{5}\right)$ are satisfied. Then, SBVP (2) has at least two solutions $u_{*}$ and $u^{*}$ in $C^{n}[(0,1), E] \cap C^{n-2}[J, E]$, satisfying

$$
0<\left\|u_{*}\right\|_{n-2}<R_{0}<\left\|u^{*}\right\|_{n-2} .
$$

Proof. Suppose that the conditions $\left(H_{1}\right),\left(H_{2}\right)$, and $\left(H_{4}\right)$ are satisfied. For a $l \in\{0,1,2, \ldots, n-2\}, 0<\delta<1 / 2$, let $M>$ $(n-1-l) ! / \delta^{n-1-l}\left(1-(1-\delta)^{n-1-l}\right)(1-2 \delta)$. There is a $0<\beta<R_{0}$, such that

$$
\begin{aligned}
& \varphi\left(f\left(t, u(t), u^{\prime}(t), \ldots, u^{(n-2)}(t),(T u)(t),(S u)(t)\right)\right) \\
& \quad \geq M \varphi\left(u^{(l)}(t)\right), \\
& t \in[\delta, 1-\delta], u^{(i)} \in P_{1} \backslash\{\theta\},(i=0,1, \ldots, n-2),\|u\|_{n-2} \leq \beta .
\end{aligned}
$$

Now, for any $0<r_{1}<\beta$, we show that

$$
A u \Varangle_{1} u, \quad u \in Q,\|u\|_{n-2}=r_{1} \text {, }
$$

in which $\leq_{1}$ is partial ordering defined by $Q$. In fact, suppose that there is a $u_{1} \in Q,\left\|u_{1}\right\|_{n-2}=r_{1}$, such that $A u_{1} \leq_{1} u_{1}$. Then, for $l \in\{0,1,2, \ldots, n-2\}, t \in[\delta, 1-\delta]$, we have

$$
\begin{aligned}
& u_{1}^{(l)}(t) \geq\left(A u_{1}\right)^{(l)}(t)=\int_{0}^{1} G_{n-l}(t, s) \\
& \cdot f\left(s, u_{1}(s), u_{1}^{\prime}(s), \ldots, u_{1}^{(n-2)}(s),\left(T u_{1}\right)\right. \\
& \left.\cdot(s),\left(S u_{1}\right)(s)\right) \mathrm{d} s \geq \frac{\delta^{n-1-l}\left(1-(1-\delta)^{n-1-l}\right)}{(n-1-l) !} \\
& \cdot \int_{\delta}^{1-\delta} f\left(s, u_{1}(s), u_{1}^{\prime}(s), \ldots, u_{1}^{(n-2)}(s),\left(T u_{1}\right)\right. \\
& \left.\cdot(s),\left(S u_{1}\right)(s)\right) \mathrm{d} s .
\end{aligned}
$$


By (76) and (78), one can see that

$$
\begin{gathered}
\varphi\left(u_{1}^{(l)}(t)\right) \geq \varphi\left[\frac{\delta^{n-1-l}\left(1-(1-\delta)^{n-1-l}\right)}{(n-1-l) !} \int_{\delta}^{1-\delta} f(s\right. \\
\left.\left.u_{1}(s), u_{1}^{\prime}(s), \ldots, u_{1}^{(n-2)}(s),\left(T u_{1}\right)(s),\left(S u_{1}\right)(s)\right) \mathrm{d} s\right] \\
=\frac{\delta^{n-1-l}\left(1-(1-\delta)^{n-1-l}\right)}{(n-1-l) !} \int_{\delta}^{1-\delta} \varphi\left[f \left(s, u_{1}(s)\right.\right. \\
\left.\left.u_{1}^{\prime}(s), \ldots, u_{1}^{(n-2)}(s),\left(T u_{1}\right)(s),\left(S u_{1}\right)(s)\right)\right] \mathrm{d} s \\
\geq \frac{\delta^{n-1-l}\left(1-(1-\delta)^{n-1-l}\right)}{(n-1-l) !} \int_{\delta}^{1-\delta} M \varphi\left(u_{1}^{(l)}(s)\right) \mathrm{d} s
\end{gathered}
$$

Hence,

$$
\begin{aligned}
& \int_{\delta}^{1-\delta} \varphi\left(u_{1}^{(l)}(t)\right) \mathrm{d} t \\
& \quad \geq \frac{\delta^{n-1-l}\left(1-(1-\delta)^{n-1-l}\right)(1-2 \delta)}{(n-1-l) !} \\
& \cdot M \int_{\delta}^{1-\delta} \varphi\left(u_{1}^{(l)}(s)\right) \mathrm{d} s .
\end{aligned}
$$

Then, it follows from $M\left(\delta^{n-1-l}\left(1-(1-\delta)^{n-1-l}\right)(1-2 \delta) /(n-\right.$ $1-l) !)>1, \varphi\left(u_{1}^{(l)}(t)\right) \geq 0$ and $(80)$ that

$$
\varphi\left(u_{1}^{(l)}(t)\right)=0, \quad \forall t \in[\delta, 1-\delta] .
$$

Since $u_{1} \in Q$, by (24), we get

$$
\begin{aligned}
\left\|u_{1}^{(l)}(t)\right\| & \geq \frac{t^{n-1-l}}{(n-1-l) !}\left\|u_{1}^{(n-2)}\right\|_{c} \\
& \geq \frac{\delta^{n-1-l}}{(n-1-l) !}\left\|u_{1}^{(n-2)}\right\|_{c}, \quad(\forall t \in[\delta, 1-\delta]),
\end{aligned}
$$

which implies

$$
\left\|u_{1}^{(n-2)}\right\|_{c}=0
$$

It contradicts $\left\|u_{1}\right\|_{n-2}=r_{1}>0$. Thus, (77) holds.

On the other hand, by conditions $\left(H_{1}\right),\left(H_{2}\right)$, and $\left(H_{5}\right)$, for $l \in\{0,1,2, \ldots, n-2\}, 0<\delta<1 / 2$, let

$$
M>\frac{(n-1-l) !}{\delta^{n-1-l}\left(1-(1-\delta)^{n-1-l}\right)(1-2 \delta)} .
$$

There exists $\tau>0$ such that

$$
\begin{aligned}
& \varphi\left(f\left(t, u(t), u^{\prime}(t), \ldots, u^{(n-2)}(t),(T u)(t),(S u)(t)\right)\right) \\
& \quad \geq M \varphi\left(u^{(n-2)}(t)\right), \\
& t \in[\delta, 1-\delta], u^{(i)} \in P_{1} \backslash\{\theta\},(i=0,1, \ldots, n-2),\left\|u^{(l)}\right\| \geq \tau .
\end{aligned}
$$

Set

$$
R_{1}>\max \left\{\frac{(n-1-l) ! \tau}{\delta^{n-1-l}}, R_{0}\right\}
$$

We show that

$$
A u \Varangle_{1} u, \quad u \in Q,\|u\|_{n-2}=R_{1} .
$$

In fact, by (24), if there is $u_{1} \in Q,\left\|u_{1}\right\|_{n-2}=R_{1}$ such that $A u_{1} \leq{ }_{1} u_{1}$, then

$$
\left\|u_{1}^{(l)}(t)\right\| \geq \frac{t^{n-1-l}}{(n-1-l) !}\left\|u_{1}^{(n-2)}\right\|_{c}, \quad \forall t \in[\delta, 1-\delta] .
$$

It is easy to see by (86) and (88) that

$$
\min _{t \in[\delta, 1-\delta]}\left\|u_{1}^{(l)}(t)\right\| \geq \frac{t^{n-1-l}}{(n-1-l) !}\left\|u_{1}\right\|_{n-2}=\delta R_{1}>\tau .
$$

In the same way, similar to the proof of (77), (87) holds.

Finally, by condition $\left(\mathrm{H}_{2}\right)$, one can see

$$
A u \nsupseteq_{1} u, \quad u \in Q,\|u\|_{n-2}=R_{0} .
$$

In fact, if there is $u_{1} \in Q,\left\|u_{1}\right\|_{n-2}=R_{0}$ such that $A u_{1} \geq_{1} u_{1}$, then

$$
\begin{aligned}
\theta \leq & u_{1}^{(n-2)}(t) \leq\left(A u_{1}\right)^{(n-2)}(t)=\int_{0}^{1} G_{2}(t, s) \\
& \cdot f\left(s, u_{1}(s), u_{1}^{\prime}(s), \ldots, u_{1}^{(n-2)}(s),\left(T u_{1}\right)\right.
\end{aligned}
$$

$$
\left.\cdot(s),\left(S u_{1}\right)(s)\right) \mathrm{d} s, \quad \forall t \in J .
$$

Hence,

$$
\begin{aligned}
R_{0} & =\left\|u_{1}\right\|_{n-2} \leq \int_{0}^{1} s(b(s) \\
& +\sum_{i=0}^{n-2} a_{i}(s) g_{i}\left(\frac{s^{n-1-i}}{(n-1-i) !} R_{0}\right)\left(1+\frac{h_{i}\left(R_{0}\right)}{g_{i}\left(R_{0}\right)}\right) \\
& \left.+a_{n-1}(s) h_{n-1}\left(k^{*} R_{0}\right)+a_{n}(s) h_{n}\left(h^{*} R_{0}\right)\right) \mathrm{d} s \\
& <R_{0} .
\end{aligned}
$$

This is a contradiction. Therefore, (90) is true.

Above all, we set $R=R_{1}, r=r_{1}$. By $\left(H_{1}\right),\left(H_{2}\right),\left(H_{3}\right)$, and Lemma 15 , we know that $A: \bar{Q}_{R_{1}} \backslash Q_{r_{1}} \rightarrow Q$ is a strict set contraction. By virtue of (77), (87), and (90), applying Lemma 4 twice, we obtain that operator $A$ has at least one fixed point in $Q_{R_{1}} \backslash \bar{Q}_{R_{0}}$ and $Q_{R_{0}} \backslash \bar{Q}_{r_{1}}$, respectively. By Lemma 13, SBVP (2) has at least two solutions $u_{*} \in Q_{R_{1}} \backslash \bar{Q}_{R_{0}}$ and $u^{*} \in Q_{R_{0}} \backslash \bar{Q}_{r_{1}}$ satisfying $0<\left\|u_{*}\right\|_{n-2}<R_{0}<\left\|u^{*}\right\|_{n-2}$.

An application of Theorem 16 is as follows. 
Example 17. Consider SBVP of infinite system for scalar nonlinear third-order singular integrodifferential equations:

$$
\begin{aligned}
-u_{n}^{\prime \prime \prime}(t)= & \frac{1}{4 n \sqrt{t(1-t)}}+\frac{t^{4}}{6 n^{3 / 2}\left(u_{2 n}(t)\right)^{1 / 2}} \\
& +\frac{t^{4} \sqrt{u_{n}(t)}}{4(n+2)}+\frac{1-t^{1 / 2}}{5 n\left(u_{(n+1)}^{\prime}(t)\right)^{1 / 3}} \\
& +\frac{1-t^{1 / 2}}{3(n+1)^{2}} \sup _{n \in\{1,2, \ldots\}}\left(u_{n}^{\prime}(t)\right)^{2} \\
& +\frac{t^{2}}{4} \int_{0}^{t} \frac{1}{1+(t-s)} u_{n}(s) \mathrm{d} s \\
& +\frac{t^{5}}{6} \int_{0}^{1}(t+s) u_{n}(s) \mathrm{d} s, \quad 0<t<1 ; \\
u_{n}(0)= & u_{n}^{\prime}(0)=u_{n}^{\prime \prime}(1)=0, \quad(n=1,2, \ldots) .
\end{aligned}
$$

Conclusion 18. Infinite system (93) has at least two solutions:

$$
\begin{gathered}
\left\{u_{n}(t)\right\}, \quad(n=1,2,3, \ldots), \\
\left\{v_{n}(t)\right\}, \quad(n=1,2,3, \ldots)
\end{gathered}
$$

such that

$$
\begin{aligned}
& u_{n}(t) \longrightarrow 0, \\
& v_{n}(t) \longrightarrow 0,
\end{aligned}
$$$$
\text { as } n \longrightarrow \infty \text {, }
$$

$$
0<\sup _{n} \max _{t \in[0,1]}\left\{u_{n}^{\prime \prime}(t)\right\}<1<\sup _{n} \max _{t \in[0,1]}\left\{v_{n}^{\prime \prime}(t)\right\} .
$$

Proof. Let $J=[0,1], E=: C_{0}=\left\{u=\left(u_{1}, u_{2}, \ldots, u_{n}, \ldots\right)\right.$ : $\left.u_{n} \rightarrow 0\right\}$ with norm $\|u\|=\sup _{n}\left|u_{n}\right|$, and $P=\{u=$ $\left.\left(u_{1}, \ldots, u_{n}, \ldots\right) \in C_{0}: u_{n} \geq 0, n=1,2, \ldots\right\}$. Obviously $P$ is a normal cone in $E$ and the normal constant $N=1$. Let $u_{0}=\left(1 / 4,1 / 9, \ldots, 1 /(n+1)^{2}, \ldots\right)$. Then, it is easy to see $u_{0} \in P, 0<\left\|u_{0}\right\|=1 / 4<1$, and $P_{1}=\left\{u \in P: u_{n} \geq\right.$ $\left.u_{0 n}\|u\|, n=1,2, \ldots\right\}$. Infinite system (93) can be regarded as SBVP of the form (2) in $E$. In this situation,

$$
\begin{aligned}
k(t, s) & =\frac{1}{1+(t-s)} \in C\left[D, R_{+}\right], \\
\qquad(D=\{(t, s) \in J \times J: s \leq t\}), & \\
h(t, s) & =t+s \in C\left[J \times J, R_{+}\right], \\
u & =\left(u_{1}, u_{2}, \ldots, u_{n}, \ldots\right), \\
v & =\left(v_{1}, v_{2}, \ldots, v_{n}, \ldots\right), \\
w & =\left(w_{1}, w_{2}, \ldots, w_{n}, \ldots\right), \\
x & =\left(x_{1}, x_{2}, \ldots, x_{n}, \ldots\right),
\end{aligned}
$$

$$
f=\left(f_{1}, f_{2}, \ldots, f_{n}, \ldots\right), \text { with }
$$

$$
\begin{aligned}
f_{n}(t, u, v, w, x)= & \frac{1}{4 n \sqrt{t(1-t)}}+\frac{t^{4}}{6 n^{3 / 2}\left(u_{2 n}\right)^{1 / 2}} \\
& +\frac{t^{4} \sqrt{u_{n}}}{4(n+2)}+\frac{1-t^{1 / 2}}{5 n\left(v_{(n+1)}\right)^{1 / 3}} \\
& +\frac{1-t^{1 / 2}}{3(n+1)^{2}}\|v\|^{2}+\frac{t^{2}}{4} w_{n}+\frac{t^{5}}{6} x_{n} .
\end{aligned}
$$

Obviously, for $(t, u, v, w, x) \in(0,1) \times P_{1} \backslash\{\theta\} \times P_{1} \backslash\{\theta\} \times P_{1} \times P_{1}$, it is easy to see that

$$
\begin{aligned}
6 n^{3 / 2}\left(u_{2 n}\right)^{1 / 2} & \geq \frac{6 n^{3 / 2}}{2 n+1}\|u\|^{1 / 2}>0, \\
\frac{\|u\|^{1 / 2}}{4(n+2)} & \geq \frac{\left(u_{n}\right)^{1 / 2}}{4(n+2)} \geq \frac{1}{4(n+2)(n+1)}\|u\|^{1 / 2}, \\
5 n\left(v_{(n+1)}\right)^{1 / 3} & \geq 5 n\left(\frac{1}{n+2}\right)^{2 / 3}\|v\|^{1 / 3}>0, \\
\frac{1}{12}\|v\|^{2} & \geq \frac{1}{3(n+1)^{2}}\|v\|^{2}, \\
w_{n} & \geq\left(\frac{1}{n+1}\right)^{2}\|w\|, \\
x_{n} & \geq\left(\frac{1}{n+1}\right)^{2}\|x\|,
\end{aligned}
$$

$$
n=1,2, \ldots,
$$

which implies that

$$
\begin{aligned}
\left|f_{n}\right| \leq & \frac{1}{4 n \sqrt{t(1-t)}}+\frac{(2 n+1) t^{4}}{6 n^{3 / 2}\|u\|^{1 / 2}}+\frac{\|u\|^{1 / 2} t^{4}}{4(n+2)} \\
& +\frac{1-t^{1 / 2}}{5 n(1 /(n+2))^{2 / 3}\|v\|^{1 / 3}}+\frac{1-t^{1 / 2}}{3(n+1)^{2}}\|v\|^{2} \\
& +\frac{t^{2}}{4} w_{n}+\frac{t^{5}}{6} x_{n}, \quad n=1,2, \ldots
\end{aligned}
$$

Since $u_{n} \rightarrow 0, v_{n} \rightarrow 0, w_{n} \rightarrow 0, x_{n} \rightarrow 0$, as $n \rightarrow+\infty$, one can see that $\left|f_{n}\right| \rightarrow 0$, as $n \rightarrow+\infty$. That is, $f \in E$. Obviously, $f \in P$. By (99), we can see

$$
\begin{aligned}
\|f\| \leq & \frac{1}{4 \sqrt{t(1-t)}}+\frac{t^{4}}{2\|u\|^{1 / 2}}+\frac{\|u\|^{1 / 2} t^{4}}{12} \\
& +\frac{3^{2 / 3}\left(1-t^{1 / 2}\right)}{5\|v\|^{1 / 3}}+\frac{1-t^{1 / 2}}{12}\|v\|^{2}+\frac{t^{2}}{4}\|w\| \\
& +\frac{t^{5}}{6}\|x\| .
\end{aligned}
$$


On the other hand, it follows from (97) and (98) that

$$
\begin{aligned}
& f_{n}(t, u, v, w, x) \geq \frac{1}{4 n \sqrt{t(1-t)}}+\frac{t^{4}}{6 n^{3 / 2}\|u\|^{1 / 2}} \\
& +\frac{t^{4}}{4(n+2)(n+1)}\|u\|^{1 / 2} \\
& +\frac{1-t^{1 / 2}}{5 n(1 /(n+2))^{2 / 3}\|v\|^{1 / 3}}+\frac{1-t^{1 / 2}}{3(n+1)^{2}}\|v\|^{2}+\frac{t^{2}}{4} \\
& \cdot w_{n}+\frac{t^{5}}{6} x_{n} \geq \frac{1}{(n+1)^{2}}\left(\frac{(n+1)^{2}}{4 n \sqrt{t(1-t)}}\right. \\
& +\frac{(n+1)^{2} t^{4}}{6 n^{3 / 2}\|u\|^{1 / 2}+\frac{(n+1) t^{4}}{4(n+2)}\|u\|^{1 / 2}} \\
& +\frac{(n+2)^{2 / 3}(n+1)^{2}\left(1-t^{1 / 2}\right)}{5 n\|v\|^{1 / 3}}+\frac{1-t^{1 / 2}}{3}\|v\|^{2} \\
& \left.+\frac{t^{2}}{4}\|w\|+\frac{t^{5}}{6}\|x\|\right), \quad n=1,2, \ldots
\end{aligned}
$$

It is easy to get

$$
\begin{aligned}
\frac{(n+1)^{2}}{n} & \geq 4, \\
\frac{(n+1)^{2}}{n^{3 / 2}} & \geq 3, \\
\frac{n+1}{4(n+2)} & \geq \frac{1}{6}, \\
\frac{(n+2)^{2 / 3}(n+1)^{2}}{5 n} & \geq 4 \frac{3^{2 / 3}}{5},
\end{aligned}
$$

$$
n=1,2, \ldots
$$

It follows from (100), (101), and (102) that

$$
\begin{gathered}
f_{n}(t, u, v, w, x) \geq \frac{1}{(n+1)^{2}}\left(\frac{1}{4 \sqrt{t(1-t)}}+\frac{t^{4}}{2\|u\|^{1 / 2}}\right. \\
+\frac{\|u\|^{1 / 2} t^{4}}{6}+4 \frac{3^{2 / 3}\left(1-t^{1 / 2}\right)}{5\|v\|^{1 / 3}}+\frac{1-t^{1 / 2}}{3}\|v\|^{2} \\
\left.+\frac{t^{2}}{4}\|w\|+\frac{t^{5}}{6}\|x\|\right) \geq \frac{1}{(n+1)^{2}}\|f\|=u_{0 n}\|f\|, \\
n=1,2, \ldots
\end{gathered}
$$

So, $f \in C\left[(0,1) \times P_{1} \backslash\{\theta\} \times P_{1} \backslash\{\theta\} \times P_{1} \times P_{1}, P_{1}\right]$ and $f\left(t, v_{0}, v_{1}, v_{2}, v_{3}\right)$ is singular at $v_{i}=\theta(i=0,1), t=0$, and $/$ or $t=1$. Thus, by (100), condition $\left(H_{1}\right)$ holds for

$$
\begin{aligned}
b(t) & =\frac{1}{4 \sqrt{t(1-t)}}, \\
a_{0}(t) & =\frac{1}{2} t^{4}, \\
a_{1}(t) & =\frac{1}{2}\left(1-t^{1 / 2}\right), \\
a_{2}(t) & =\frac{t^{2}}{4} \\
a_{3}(t) & =\frac{t^{5}}{6} \\
g_{0}(y) & =\frac{1}{y^{1 / 2}}, \\
g_{1}(y) & =\frac{1}{y^{1 / 3}}, \\
h_{2}(y) & =h_{3}(y)=y, \\
h_{0}(y) & =y^{1 / 2}, \\
h_{1}(y) & =y^{2} .
\end{aligned}
$$

For any $R>r>0$, by (100), we have, with $k^{*}=1$ and $h^{*}=2$,

$$
\begin{aligned}
& \int_{0}^{1}\left(\frac{s}{4 \sqrt{s(1-s)}}+\frac{\sqrt{2} s^{4}}{2 \sqrt{r}}(1+R)\right. \\
& \left.\quad+\frac{s\left(1-s^{1 / 2}\right)}{2 \sqrt[3]{s r}}\left(1+R^{4 / 3}\right)+\frac{s^{3}}{4} R+\frac{s^{6}}{6} 2 R\right) \mathrm{d} s \\
& \quad<+\infty
\end{aligned}
$$

On the other hand, taking $R_{0}=1$, by (105), we have

$$
\begin{gathered}
\int_{0}^{1}\left(\frac{s}{4 \sqrt{s(1-s)}}+\sqrt{2} s^{4}+\frac{s\left(1-s^{1 / 2}\right)}{2 \sqrt[3]{s}}(1+1)+\frac{s^{3}}{4}\right. \\
\left.+\frac{s^{6}}{6} 2\right) \mathrm{d} s=\frac{\pi}{8}+\frac{\sqrt{2}}{5}+\frac{9}{65}+\frac{1}{16}+\frac{1}{21}<1 .
\end{gathered}
$$

By (105) and (106), condition $\left(\mathrm{H}_{2}\right)$ is satisfied.

For any $R>r>0,[a, b] \subset(0,1)$, it is clear that $f$ is uniformly continuous on

$[a, b]$

$$
\times \underbrace{\overline{P_{1_{R}}} \backslash P_{1_{r}} \times \overline{P_{1_{R}}} \backslash P_{1_{r}} \times \cdots \times \overline{P_{1_{R}}} \backslash P_{1_{r}} \times \overline{P_{1_{R}}} \times \overline{P_{1_{R}}}}_{n+1} .
$$


Let $f=f^{1}+f^{2}+f^{3}$, with

$$
\begin{aligned}
& f^{1}=\left(f_{1}^{1}, f_{2}^{1}, \ldots, f_{n}^{1}, \ldots\right), \\
& f^{2}=\left(f_{1}^{2}, f_{2}^{2}, \ldots, f_{n}^{2}, \ldots\right), \\
& f^{3}=\left(f_{1}^{3}, f_{2}^{3}, \ldots, f_{n}^{3}, \ldots\right),
\end{aligned}
$$

where

$$
\begin{aligned}
f_{n}^{1}(t, u, v, w, x)= & \frac{1}{4 n \sqrt{t(1-t)}}+\frac{t^{4}}{6 n^{3 / 2}\left(u_{2 n}\right)^{1 / 2}} \\
& +\frac{t^{4} \sqrt{u_{n}}}{4(n+2)}+\frac{1-t^{1 / 2}}{5 n\left(v_{(n+1)}\right)^{1 / 3}} \\
& +\frac{1-t^{1 / 2}}{3(n+1)^{2}}\|v\|^{2}, \\
f_{n}^{2}(t, u, v, w, x)= & \frac{t^{4}}{4} w_{n}, \\
f_{n}^{3}(t, u, v, w, x)= & \frac{t^{5}}{6} x_{n}, \quad n=1,2, \ldots
\end{aligned}
$$

For any

$$
\begin{aligned}
z= & \left(z_{1}, z_{2}, \ldots, z_{n}, \ldots\right) \in f^{1}\left(t, B_{0}, B_{1}, B_{2}, B_{3}\right) \\
& \left(\forall t \in[a, b], B_{0}, B_{1} \subset \overline{P_{1 R}} \backslash P_{1 r}, B_{2}, B_{3} \subset \overline{P_{1 R}}\right),
\end{aligned}
$$

by (99) and (109), we get

$$
\begin{aligned}
&\left|z_{n}\right| \leq \frac{1}{4 n \sqrt{a(1-b)}}+\frac{(2 n+1) b^{4}}{6 n^{3 / 2} r^{1 / 2}}+\frac{R^{1 / 2} b^{4}}{4(n+2)} \\
&+\frac{1-a^{1 / 2}}{5 n(1 /(n+2))^{2 / 3} r^{1 / 3}}+\frac{1-a^{1 / 2}}{3(n+1)^{2}} R^{2}, \\
& n=1,2, \ldots .
\end{aligned}
$$

So, the relative compactness of $f^{1}\left(t, B_{0}, B_{1}, B_{2}, B_{3}\right)$ in $C_{0}$ follows directly from a known result (see [21]): a bounded set $X$ of $C_{0}$ is relatively compact if and only if

$$
\lim _{n \rightarrow \infty}\left\{\sup _{z \in X}\left[\max \left\{\left|Z_{k}\right|: k \geq n\right\}\right]\right\}=0 .
$$

Hence,

$$
\begin{aligned}
& \alpha\left(f^{1}\left(t, B_{0}, B_{1}, B_{2}, B_{3}\right)\right)=0, \\
& \quad \forall t \in[a, b], B_{0}, B_{1} \subset \overline{P_{1 R}} \backslash P_{1 r}, B_{2}, B_{3} \subset \overline{P_{1 R}} .
\end{aligned}
$$

By (109), it is easy to get

$$
\begin{aligned}
& \alpha\left(f^{2}\left(t, B_{0}, B_{1}, B_{2}, B_{3}\right)\right) \leq \frac{1}{4} \alpha\left(B_{2}\right), \\
& \forall t \in(0,1), B_{0}, B_{1} \subset \overline{P_{1 R}} \backslash P_{1 r}, B_{2}, B_{3} \subset \overline{P_{1 R}}, \\
& \alpha\left(f^{3}\left(t, B_{0}, B_{1}, B_{2}, B_{3}\right)\right) \leq \frac{1}{6} \alpha\left(B_{3}\right), \\
& \forall t \in(0,1), B_{0}, B_{1} \subset \overline{P_{1 R}} \backslash P_{1 r}, B_{2}, B_{3} \subset \overline{P_{1 R}} .
\end{aligned}
$$

Combining this with (109), (113), and (114), one can see

$$
\begin{aligned}
& \alpha\left(f\left(t, B_{0}, B_{1}, B_{2}, B_{3}\right)\right) \\
& \leq \alpha\left(f^{1}\left(t, B_{0}, B_{1}, B_{2}, B_{3}\right)\right) \\
&+\alpha\left(f^{2}\left(t, B_{0}, B_{1}, B_{2}, B_{3}\right)\right) \\
&+\alpha\left(f^{3}\left(t, B_{0}, B_{1}, B_{2}, B_{3}\right)\right) \\
& \leq \frac{1}{4} \alpha\left(B_{2}\right)+\frac{1}{6} \alpha\left(B_{3}\right), \\
& \quad \forall t \in[a, b], B_{0}, B_{1} \subset \overline{P_{1 R}} \backslash P_{1 r}, B_{2}, B_{3} \subset \overline{P_{1 R}} .
\end{aligned}
$$

Therefore, condition $\left(\mathrm{H}_{3}\right)$ holds.

For any $u \in P_{1}$, define $\varphi$ by $\varphi(u)=u_{1}$. It is easy to see $\varphi \in P_{1}^{*},\|\varphi\|=1$. Let $[a, b]=[1 / 4,3 / 4]$, for

$$
(t, u, v, w, x) \in\left[\frac{1}{4}, \frac{3}{4}\right] \times P_{1} \backslash\{\theta\} \times P_{1} \backslash\{\theta\} \times P_{1}
$$

$$
\times P_{1} \text {, }
$$

and it is easy to see $0<(1 / 4)\|u\| \leq u_{1} \leq\|u\|, 0<(1 / 4)\|v\| \leq$ $v_{1} \leq\|v\|$. Thus, (97), (101), and (102) imply that

$$
\begin{aligned}
& \lim _{\|u\| \rightarrow 0} \frac{\varphi(f(t, u, v, w, x))}{\varphi(u)}=\lim _{\|u\| \rightarrow 0} \frac{f_{1}(t, u, v, w, x)}{u_{1}} \\
& \geq \lim _{\|u\| \rightarrow 0} \frac{1 / 2^{11}\|u\|^{1 / 2}}{u_{1}} \geq \lim _{\|u\| \rightarrow 0} \frac{1}{2^{11}}=u \|^{3 / 2}=+\infty, \\
& \lim _{\|v\| \rightarrow+\infty} \frac{\varphi(f(t, u, v, w, x))}{\varphi(v)}=\lim _{\|v\| \rightarrow+\infty} \frac{f_{1}(t, u, v, w, x)}{v_{1}} \\
& \geq \lim _{\|v\| \rightarrow+\infty} \frac{\|v\|^{2}}{24 v_{1}} \geq \lim _{\|v\| \rightarrow+\infty} \frac{\|v\|}{24}=+\infty .
\end{aligned}
$$

The conditions $\left(H_{4}\right)$ and $\left(H_{5}\right)$ follow from (118) and (119). It is easy to see that

$$
\gamma=\frac{1}{4}+\frac{1}{3}=\frac{7}{12}<1
$$

for

$$
\begin{aligned}
& L_{0}=0, \\
& L_{1}=0, \\
& L_{2}=\frac{1}{4}, \\
& L_{3}=\frac{1}{6} .
\end{aligned}
$$

Therefore, by Theorem 16, our conclusion holds. 


\section{Conflict of Interests}

The authors declare that they have no competing interests.

\section{Authors' Contribution}

All authors typed, read, and approved the final paper.

\section{Acknowledgments}

The authors would like to thank the reviewers for carefully reading this paper and making valuable comments and suggestions. The project is supported by the National Natural Science Foundation of P.R. China (71272119), Taishan Scholar Program of Shandong Province, Major Project of National Social Science Foundation of P.R. China (12\&ZD069), Social Science Foundation of Shandong Province (13CJRJ07), and Teaching and Research Projects of Qi Lu Normal University (201306).

\section{References}

[1] S. D. Taliaferro, "A nonlinear singular boundary value problem," Nonlinear Analysis: Theory, Methods \& Applications, vol. 3, no. 6, pp. 897-904, 1979.

[2] A. Callegari and A. Nachman, "Some singular, nonlinear differential equations arising in boundary layer theory," Journal of Mathematical Analysis and Applications, vol. 64, no. 1, pp. 96$105,1978$.

[3] C. D. Luning and W. L. Perry, "Positive solutions of negative exponent generalized Emden-Fowler boundary value problems," SIAM Journal on Mathematical Analysis, vol. 12, no. 6, pp. 874-879, 1981.

[4] A. Nachman and A. Callegari, "A nonlinear singular boundary value problem in the theory of pseudoplastic fluids," SIAM Journal on Applied Mathematics, vol. 38, no. 2, pp. 275-281, 1980.

[5] R. P. Agarwal, D. Franco, and D. O’Regan, "Singular boundary value problems for first and second order impulsive differential equations," Aequationes Mathematicae, vol. 69, no. 1-2, pp. 8396, 2005.

[6] P. J. Y. Wong and R. P. Agarwal, "On the existence of solutions of singular boundary value problems for higher order difference equations," Nonlinear Analysis: Theory, Methods \& Applications, vol. 28, no. 2, pp. 277-287, 1997.

[7] R. P. Agarwal and D. O'Regan, "Positive solutions for ( $p, n-$ $p$ ) conjugate boundary value problems," Journal of Differential Equations, vol. 150, no. 2, pp. 462-473, 1998.

[8] R. P. Agarwal and D. O’Regan, "Multiplicity results for singular conjugate, focal, and $(n, p)$ problems," Journal of Differential Equations, vol. 170, no. 1, pp. 142-156, 2001.

[9] Y. Chen, "Multiple solutions for boundary value problems of $n$ th-order nonlinear integrodifferential equations in banach spaces," Abstract and Applied Analysis, vol. 2013, Article ID 296038, 7 pages, 2013.

[10] Y. Liu, "Positive solutions of second order singular initial value problem in Banach space," Indian Journal of Pure and Applied Mathematics, vol. 33, no. 6, pp. 833-845, 2002.

[11] Y. S. Liu, "Positive solutions of nonlinear singular boundary value problem in Banach space," Acta Mathematica Sinica, vol. 47, no. 1, pp. 131-140, 2004.
[12] L. Liu, Z. Liu, and Y. Wu, "Infinite boundary value problems for $n$ th-order nonlinear impulsive integro-differential equations in Banach spaces," Nonlinear Analysis. Theory, Methods \& Applications, vol. 67, no. 9, pp. 2670-2679, 2007.

[13] H. Zhang, L. Liu, and Y. Wu, "Positive solutions for n-th-order nonlinear impulsive singular integro-differential equations on infinite intervals in Banach spaces," Nonlinear Analysis: Theory, Methods \& Applications, vol. 70, no. 2, pp. 772-787, 2009.

[14] H. Zhang, L. Liu, and Y. Wu, "A unique positive solution for $n$ th-order nonlinear impulsive singular integro-differential equations on unbounded domains in Banach spaces," Applied Mathematics and Computation, vol. 203, no. 2, pp. 649-659, 2008.

[15] Y. Chen and B. Qin, "Multiple positive solutions for first-order impulsive singular integro-differential equations on the half line in a Banach space," Boundary Value Problems, vol. 2013, article 69, 24 pages, 2013.

[16] Y. Chen, T. Cao, and B. Qin, "Solutions for nth-order boundary value problems of impulsive singular nonlinear integrodifferential equations in Banach spaces," Boundary Value Problems, vol. 2014, article 128, 25 pages, 2014.

[17] D. Guo, "Existence of positive solutions for nth-order nonlinear impulsive singular integro-differential equations in Banach spaces," Nonlinear Analysis, Theory, Methods \& Applications, vol. 68, no. 9, pp. 2727-2740, 2008.

[18] D. Guo, "Positive solutions of an infinite boundary value problem for nth-order nonlinear impulsive singular integrodifferential equations in Banach spaces," Nonlinear Analysis: Theory, Methods \& Applications, vol. 70, no. 5, pp. 2078-2090, 2009.

[19] D. Guo, V. Lakshmikantham, and X. Liu, Nonlinear Integral Equations in Abstract Spaces, vol. 373 of Mathematics and its Applications, Kluwer Academic Publishers Group, Dordrecht, The Netherlands, 1996.

[20] D. J. Guo and V. Lakshmikantham, Nonlinear Problems in Abstract Cones, vol. 5 of Notes and Reports in Mathematics in Science and Engineering, Academic Press, Boston, Mass, USA, 1988.

[21] J. Banas and K. Goebel, Measure of Noncompactness in Banach Spaces, Marcel Dekker, New York, NY, USA, 1980. 


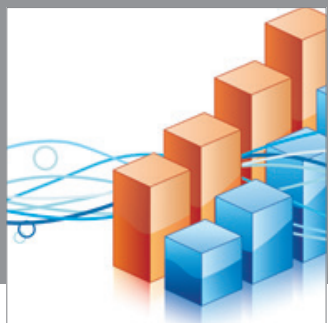

Advances in

Operations Research

mansans

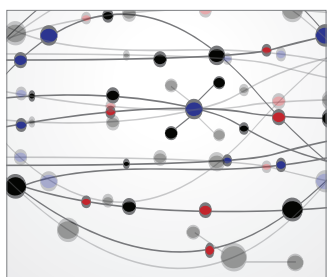

The Scientific World Journal
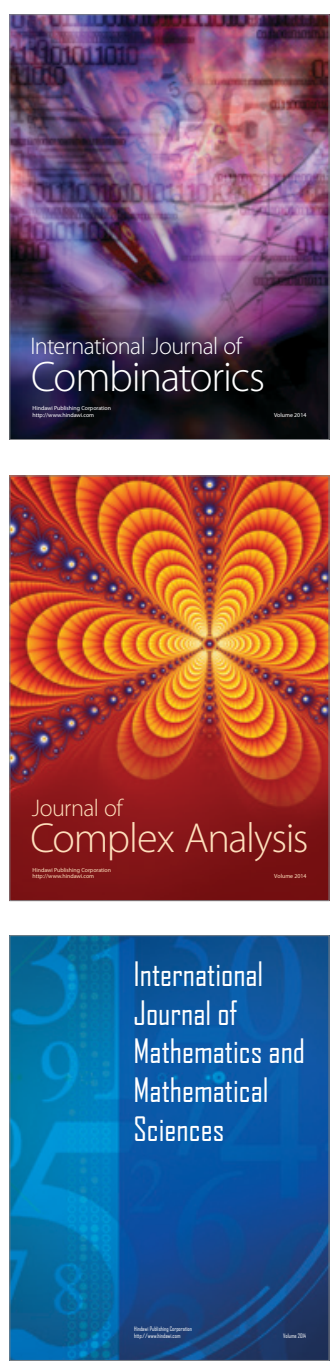
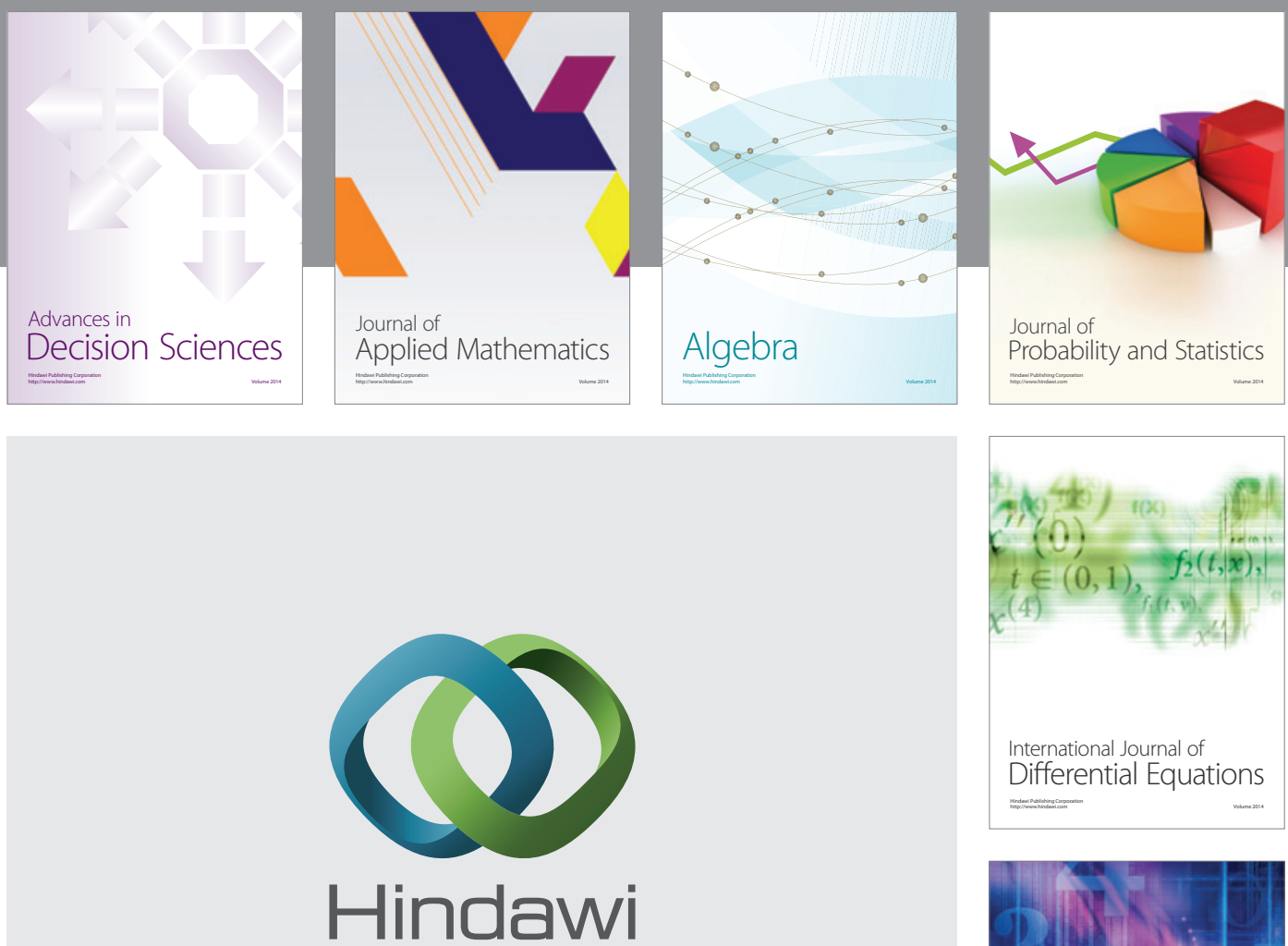

Submit your manuscripts at http://www.hindawi.com
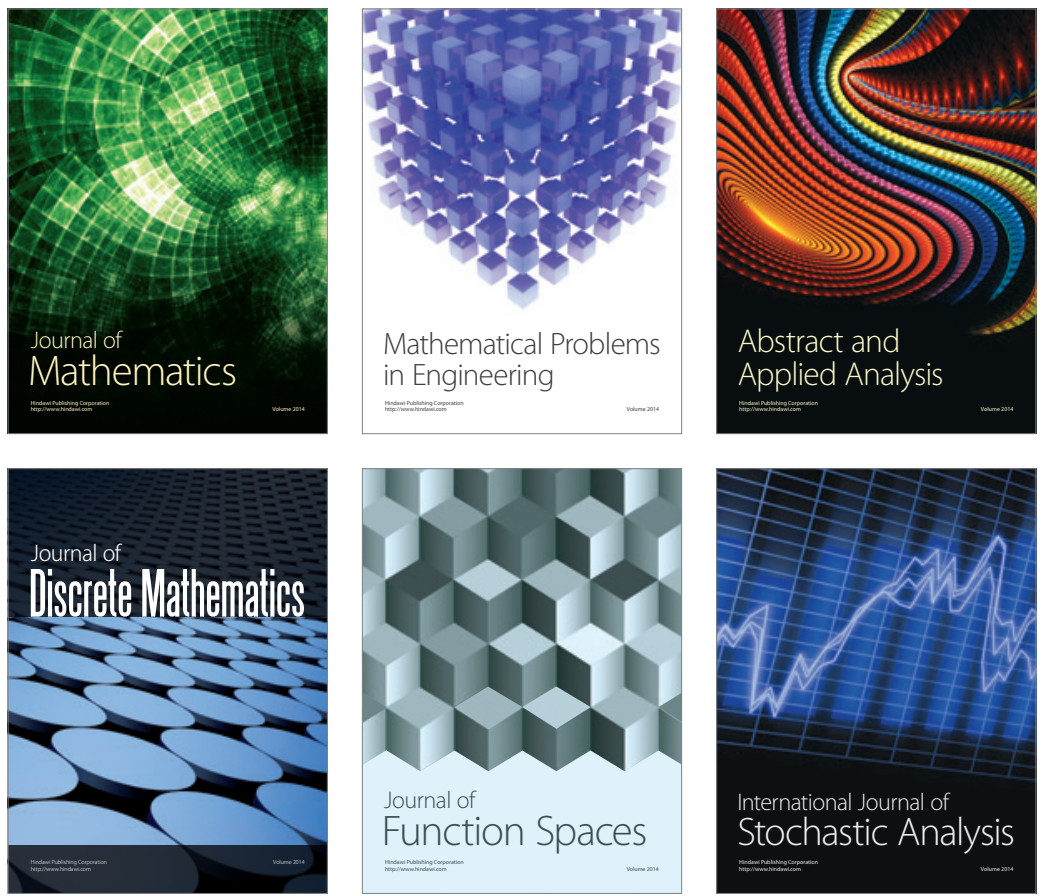

Journal of

Function Spaces

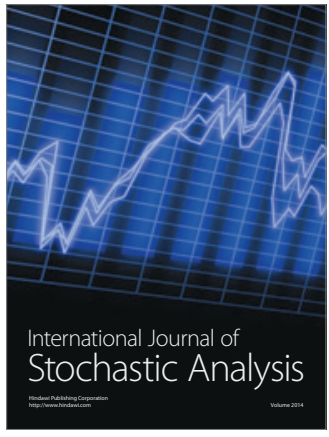

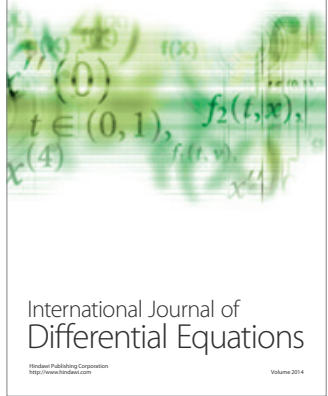
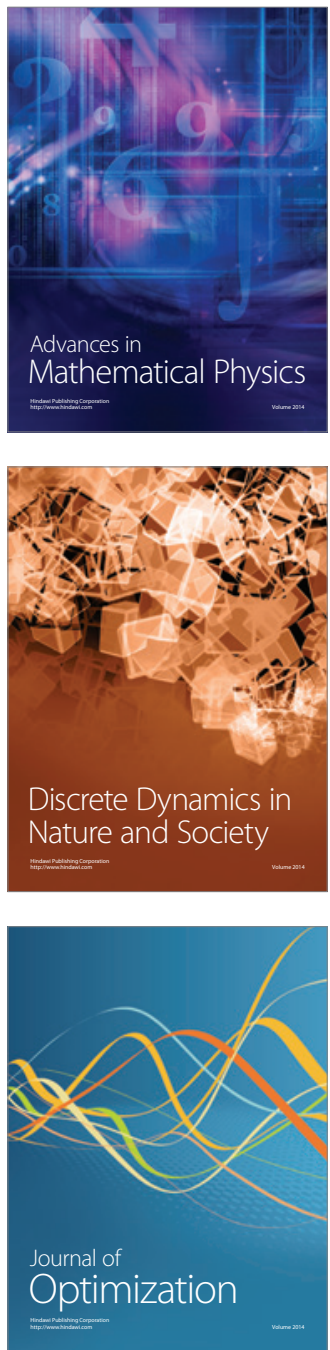